\title{
3DAP/TEM Study of Precipitation Hardened Magnesium Alloys
}

\author{
T.T. Sasaki ${ }^{1}$, T. Ohkubo ${ }^{1}$ and K. Hono ${ }^{1}$ \\ 1. Research Center for Magnetic and Spintronic Materials, National Institute for Materials Science \\ (NIMS), 1-2-1 Sengen, Tsukuba, Japan.
}

Recent intense interest in developing lighter wrought alloys revived researches on precipitation hardenable magnesium alloys. Since the age-hardening responses of magnesium alloys without rare earth elements are poor, precipitation hardening has not been used in conventional wrought magnesium alloys. However, optimizations of alloy compositions often lead to the formation of metastable nanosized precipitates during artificial aging, which substantially enhances the yield strength. In order to understand the mechanism of age-hardening behaviors of recently developed magnesium alloys, the demand for analyzing solute clusters and nano-scale precipitates in magnesium alloys is increasing. Since three-dimensional atom probe (3DAP) can visualize solute clustering processes, it is the ideal tool to investigate the pre-precipitation stages of age-hardening magnesium alloys to complement transmission electron microscopy.

3DAP analysis of magnesium alloy has been difficult because of low yield strength that causes frequent specimen rupture under a high electric field and low evaporation field. However, the use of UV-laser to assist field evaporation reduces the chance of specimen rupture, enabling reliable dataset acquisitions from magnesium alloys.

In this presentation, we show examples of the applications of UV laser assisted 3DAP to various precipitation hardenable magnesium alloys that have been carried out to understand the effect of trace elements on age hardening. Mg-5.4Sn-4.3Zn-2.0Al-0.1Na (wt\%) alloy exhibits significant enhancement of age hardening from 50 to $100 \mathrm{VHN}$ upon aging at $160{ }^{\circ} \mathrm{C}$. This is because $\mathrm{Sn}-\mathrm{Na}$ clusters form in the early stage of aging (Fig. 1), which provide heterogeneous nucleation sites for refining $\mathrm{Mg}_{2} \mathrm{Sn}$ precipitates (Fig. 2). While the Na-microalloyed extruded $\mathrm{Mg}$-Sn alloy exhibited the high strength of $350 \mathrm{MPa}$, Na leads to a significant embrittlement. To eliminate $\mathrm{Na}$, we have substituted the Sn-Na coclusters with the Zn-enriched ones by adding more $\mathrm{Zn}$. The developed Mg-5.4Sn-5.8Zn-2.0Al-0.1Mn alloy exhibited the high strength over $370 \mathrm{MPa}$ with large ductility of $\sim 14 \%$ [1]. The role of alloying elements on the age hardening behavior and microstructure evolution in $\mathrm{Mg}-\mathrm{Zn}$ and $\mathrm{Mg}-\mathrm{Ca}$ based alloys will also be discussed [2-4].

\section{References:}

[1] T. T. Sasaki et al, Acta Mateialia, 99 (2015), p. 176.

[2] T. Bhattacharjee et al, Scripta Materialia, 99 (2012), p. 967.

[3] C.L. Mendis et al, Acta Mateialia, 57 (2009), p. 5593.

[4] T. Nakata et al, Scripta Materialia, 101 (2015), p. 28 

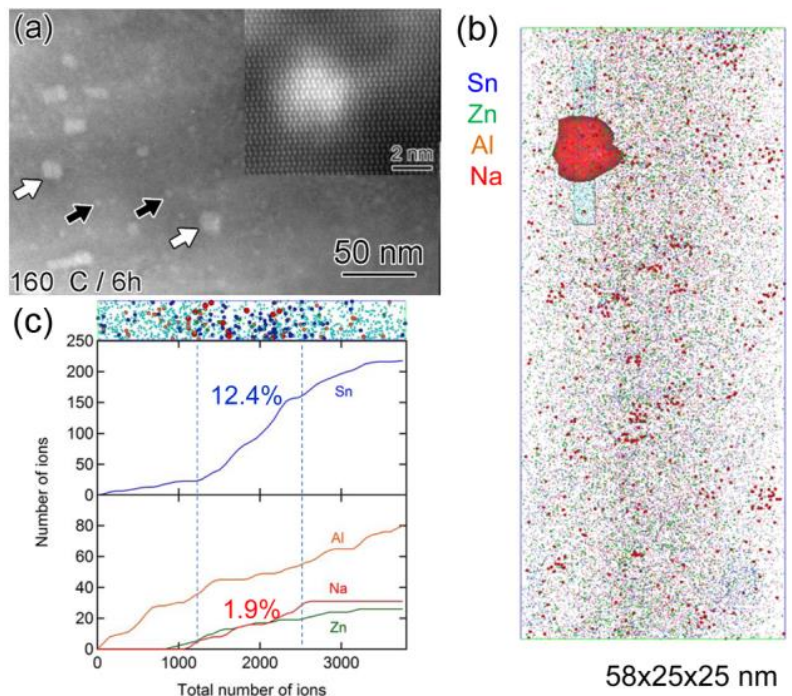

Figure 1. (a) HAADF-STEM image and (b) 3D atom map obtained from the Mg-5.4Sn-4.3Zn-2.0Al$0.1 \mathrm{Na}\left(\mathrm{wt} \%\right.$ ) alloy aged at $160^{\circ} \mathrm{C}$ for $6 \mathrm{~h}$. (c) is the ladder diagram analyzed from the volume (blue) in (b) $[1]$.
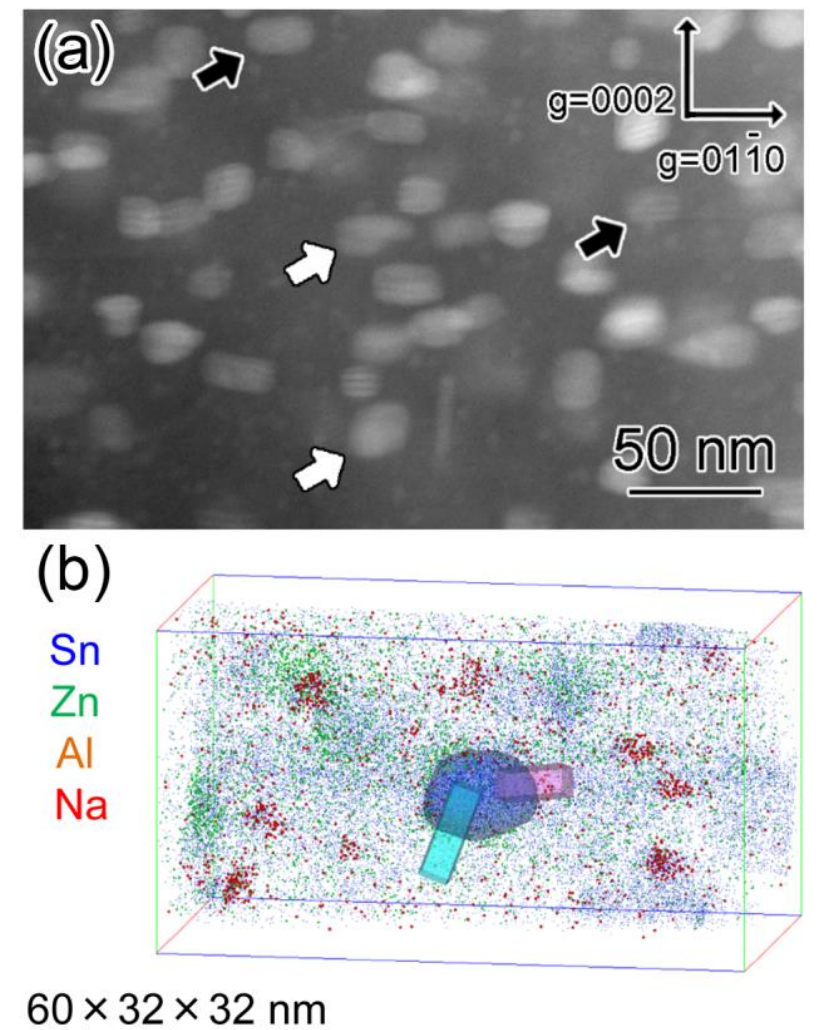

Figure 2. (a) HAADF-STEM image and (b) 3D atom map obtained from the Mg-5.4Sn-4.3Zn-2.0Al$0.1 \mathrm{Na}(\mathrm{wt} \%)$ alloy aged at $160^{\circ} \mathrm{C}$ for $16 \mathrm{~h}$ showing heterogeneous nucleation of precipitates at $\mathrm{Sn}-\mathrm{Na}$ coclusters [1]. 